\title{
A educação como direito social no Brasil e o desafio da qualidade
}

\author{
Education as a social right in Brazil and the challenge of quality \\ La educación como derecho social en Brasil y el desafío de la calidad
}

\section{Resumo}

Este artigo discute sobre os princípios constitucionais que asseguram o direito à educação pública e gratuita de qualidade no Brasil. O objetivo é analisar o texto Constitucional revelando a educação como direito social e um bem público. O problema a que esta pesquisa se propõe a responder é: Quais as diretrizes do texto Constitucional para a efetividade da educação como um direito social? A pesquisa é qualitativa e as análises partiram de um estudo bibliográfico. Do conjunto das análises realizadas, evidenciamos que o direito à educação, enquanto direito fundamental previstos na CF de 1988 e anunciado nas Constituições anteriores, não se materializa, com a qualidade social que se espera para a educação brasileira e com que o Estado democrático de direito deveria resguardar.

Palavras-chave: Direito à educação; Constituição Federal; Qualidade social.

\begin{abstract}
This article discusses the constitutional principles that ensure the right to quality public and free education in Brazil. The objective is to analyze the Constitutional text revealing education as a social right and a public good. The problem that this research proposes to answer is: What are the guidelines of the Constitutional text for the effectiveness of education as a social right? The research is qualitative and the analyzes were based on a bibliographical study. From the set of analyzes carried out, we show that the right to education, as a fundamental right provided for in the 1988 Constitution and announced in the previous Constitutions, does not materialize, with the social quality expected for Brazilian education and with the democratic rule of law should guard.

Keywords: Social rights; Fundamental Rights; Public policies.

Resumen

Este artículo analiza los principios constitucionales que garantizan el derecho a una educación pública y gratuita de calidad en Brasil. El objetivo es analizar el texto constitucional que revela la educación como un derecho social y un bien público. El problema que se propone dar respuesta a esta investigación es: ¿Cuáles son los lineamientos del texto constitucional para la efectividad de la educación como derecho social? La investigación es cualitativa y los análisis se basaron en un estudio bibliográfico. Del conjunto de análisis realizados, mostramos que el derecho a la educación, como derecho fundamental previsto en la Constitución de 1988 y anunciado en las Constituciones anteriores, no se materializa, con la calidad social esperada para la educación brasileña y con el régimen democrático. de la ley debe proteger
\end{abstract}

Palabras clave: Derecho a la educación; Constituicion Federal; Calidad social.

\section{Introdução}

A educação, enquanto dever do Estado e realidade social, não foge ao controle do Direito. A Constituição Federal a enuncia como direito de todos, dever do Estado e da família, com a tríplice função de garantir a realização plena do ser humano, inserí-lo no contexto do Estado Democrático e qualificá-lo para o mundo do trabalho. A um só tempo, a educação representa tanto um mecanismo de desenvolvimento pessoal do indivíduo, como da própria sociedade em que ele se insere.

A Constituição Federal de 1988 contempla uma série de direitos fundamentais em seu texto, abarcando tanto os direitos civis e políticos, como os direitos sociais e também os direitos de solidariedade. Contudo, a simples previsão dos referidos direitos no texto constitucional não assegura a sua eficácia, e efetividade nos casos concretos. Dessa forma, ainda que 
afirmem a existência de tais direitos sob uma eficácia imediata, nota-se a necessidade da reflexão aprofundada sobre o atual papel dos Direitos Fundamentais e seus possíveis direcionamentos em busca da real eficiência.

Assim sendo, o direito à educação está inserido no contexto dos direitos sociais, econômicos e culturais, os chamados direitos de $2^{a}$ dimensão, no âmbito dos direitos fundamentais. Nesse sentido, as prestações positivas exigidas pela população visavam a efetividade das liberdades pleiteadas pela primeira dimensão dos direitos fundamentais, posto que sem qualidade de vida, educação, saúde e igualdade fática ocorreria instabilidade nos direitos fundamentais consagrados anteriormente (primeira dimensão).

O direito à educação previsto na Constituição Federal de 1.988, está ligado ao reconhecimento da dignidade da pessoa humana, bem como, seus objetivos: construção de uma sociedade livre, justa, solidária, erradicação da pobreza, da marginalidade e redução das desigualdades sociais.

A Constituição Federal de 1988, em seu art. 212, estabelece que a União aplicará, anualmente, nunca menos de 18, e os estados, o Distrito Federal (DF) e os municípios 25\%, no mínimo, da receita líquida de impostos (RLI) na manutenção e desenvolvimento do ensino (MDE) (Brasil, 1988). Para o cálculo da RLI, somam-se, à receita dos entes federados, as transferências constitucionais recebidas e abatem-se as transferidas. Em relação aos percentuais mínimos estabelecidos na Emenda Calmon, a única alteração foi a ampliação do índice da União, que passou de 13 para $18 \%$.

Nesse sentido, importa destacar que a possibilidade de debater ou propor uma análise acreca da educação como direito social implica necessariamente em apresentar a responsabilidade do estado brasileiro em promover a devida cota de participação em seu financiamento. O financiamento da educação é uma política fundamental para implementação de uma perspectiva de educação socialemnete referenciada na qualidade.

Essa pesquisa parte da seguinte inquietação: Quais as diretrizes do texto Constitucional para a efetividade da educação como um direito social? Para responder a esse questionamento definimos como objetivo da pesquisa analisar o texto Constitucional revelando a educação como direito social e um bem público. Partimos de uma perspectiva de análise qualitativa a partir de uma pesquisa bibliográfica a partir de teorias e marcos legais.

\section{Metodologia}

A abordagem da pesquisa é qualitativa, dada a exigência do tema de pesquisa e dos objetivos propostos, uma vez que a análise dos dados buscará as informações que estão nas entrelinhas dos dados coletados. Nesta perspectiva Bogdan e Biklen (1994) asseguram que a abordagem da investigação qualitativa exige que o mundo seja examinado com a ideia de que nada é trivial, que tudo tem potencial para constituir uma pista que nos permita estabelecer uma compreensão mais esclarecedora do nosso objecto de estudo.

Assim, a pesquisa qualitativa estabelece a necessidade de um contato mais próximo entre o pesquisador e o ambiente pesquisado, ela é rica em dados descritivos, se desenvolve através de um planejamento flexível e estuda a realidade de maneira complexa e contextualizada. Conforme Bogdan e Biklen (1994), a investigação qualitativa possui algumas características principais: o investigador como o instrumento principal da pesquisa, valoriza-se mais o processo do que os resultados ou simples produtos, a análise dos dados se dá de forma indutiva e o significado dos fatos têm importância vital. Desse modo, o caminho metodológico desse estudo se pautará por estas características destacadas.

Assim, faremos uma pesquisa bibliográfica com o objetivo de fornecer o embasamento teórico- 
metodológico necessário para a análise dos dados investigados. Dessa forma, serão utilizados teses e dissertações, bem como livros e artigos científicos que abordem a temática em questão. Nesse sentido, Gil (2008, p. 50) confirma que: “A pesquisa bibliográfica é desenvolvida a partir de material já elaborado, constituído principalmente de livros e artigos científicos".

Assim, para melhor analisar o objeto aqui apresentado, utilizaremos a pesquisa documental. Nesse sentido, realizamos uma análise documental. Sobre os documentos pesquisados (leis e decretos), vale destacar que "os conteúdos dos textos ainda não tiveram nenhum tratamento analítico, são ainda matéria-prima, a partir da qual o pesquisador vai desenvolver sua investigação e análise" (SEVERINO, 2007, p. 123).

\section{Política e marcos regulatórios do financiamento da educação a partir da Constituição Federal de 1988}

As reformas educacionais desenvolvidas a partir da década de 1990 traduzem o interesse dos governos em manter a política neoliberal e em responder aos interesses do desenvolvimento mediado pela lógica econômica e a política de ajuste fiscal, com fins a adequar as contas públicas e atender aos interesses dos organismos internacionais. Nesse sentido, muitas das políticas pensadas no contexto da redemocratização, a exemplo da política de financiamento da educação, tiveram seus objetivos modificados.

Ao tratar acerca da educação nacional, em seu artigo 205, a Constituição Federal estqbelece que:

A educação, direito de todos e dever do Estado e da família, será promovida e incentivada com a colaboração da sociedade, visando ao pleno desenvolvimento da pessoa, seu preparo para o exercício da cidadania e sua qualificação para o trabalho.

E ainda, o artigo 206, da Constituição Federal, tratou desses princípios, in verbis:

Art. 206. O ensino será ministrado com base nos seguintes princípios:

I - igualdade de condições para o acesso e permanência na escola;

II- liberdade de aprender, ensinar, pesquisar e divulgar o pensamento, a arte e o saber;

III- pluralismo de ideias e de concepções pedagógicas e coexistência de instituições públicas e privadas de ensino;

IV-gratuidade do ensino público em estabelecimentos oficiais;

V-valorização dos profissionais do ensino, garantindo, na forma da lei planos de carreira para o magistério público, com piso salarial profissional e ingresso exclusivamente por concurso público de provas e títulos;

VI-gestão democrática do ensino público, na forma da lei;

VII- garantia de padrão de qualidade.

As questões relacionadas ao financiamento da educação pública ganham maior intensidade a partir da segunda metade da década de 1990 que traz, dentre suas contribuições para a educação, a mobilização de educadores, políticos e sociedade civil em torno da construção da nova Lei de Diretrizes e Bases na Educação Nacional - LDB, Lei nº. 9.394/96 com objetivos de substituir a política de organização da educação do pais em todos os níveis e modalidade, vigente desde a década de 1960. Nesta esteira, nasce o Fundo de Manutenção e Desenvolvimento do Ensino Fundamental e Valorização do Magistério (Fundef), regulamentado na Lei $\mathrm{n}^{\circ}$ 9.424/96, que teve por objetivos principais: ampliar o acesso ao ensino fundamental; reduzir as disparidades em termos de investimento entre os estados, promover a valorização dos professores desse nível de ensino com melhores salários e oportunidades de qualificação e formação continuada.

A lógica de financiamento da educação, estabelecida a partir da LDB nº 9.394/96, não apresenta grandes novidades 
em relação à CF de 1988. Nesse sentido a LDB se deteve a apresentar as principais fontes de recursos para educação, como pode ser observado no art. 68, assim como apresentar as diretrizes para as despesas com Manutenção e Desenvolvimento do Ensino - MDE de acordo com o exposto nos artigos 70 e 71.

Art. 68. Serão recursos públicos destinados à educação os originários de:

I - receita de impostos próprios da União, dos Estados, do Distrito Federal e dos Municípios;

II - receita de transferências constitucionais e outras transferências;

III - receita do salário-educação e de outras contribuições sociais;

IV - receita de incentivos fiscais;

V - outros recursos previstos em lei. (Brasil, 1996)

Neste contexto de afirmação dos dispositivos legais para subsidiar financeiramente a educação, a década de 1990 apresentou uma inovação no financiamento da educação, no que concerne à distribuição dos recursos, por meio da Emenda Constitucional - EC 14/96 que instituiu o Fundo de Manutenção e Desenvolvimento do Ensino Fundamental e Valorização do Magistério - FUNDEF.

Na sua organização o Fundef foi formado, no âmbito dos Estados, por 15\% das seguintes fontes de receita: Fundo de Participação dos Municípios (FPM); Fundo de Participação dos Estados (FPE); Imposto sobre Circulação de Mercadorias e Serviços (ICMS); Imposto sobre Produtos Industrializados, proporcional às exportações (IPI-exp); Compensação financeira decorrente da desoneração de exportações, de que trata a Lei Complementar nº 87/96 (Lei Kandir).

No art. $5^{\circ}$ da EC 14/96, que altera o Art. 60 do ADCT ficou definido que:

Art 60. Nos dez primeiros anos da promulgação desta emenda, os Estados, o Distrito Federal e os Municípios destinarão não menos de sessenta por cento dos recursos a que se refere o caput do art. 212 da Constituição Federal, a manutenção e ao desenvolvimento do ensino fundamental, com o objetivo de assegurar a universalização de seu atendimento e a remuneração condigna do magistério.

$\S 1^{\circ} \mathrm{A}$ distribuição de responsabilidades e recursos entre os estados e seus municípios a ser concretizada com parte dos recursos definidos neste artigo, na forma do disposto no art. 211 da Constituição Federal, e assegurada mediante a criação, no âmbito de cada Estado e do Distrito Federal, de um fundo de manutenção e desenvolvimento do ensino fundamental e de valorização do magistério, de natureza contábil.

Essa reorganização na distribuição dos recursos destinados à educação, por meio do Fundef, expressa a prioridade no ensino fundamental em detrimento de outras etapas da educação básica. Todavia, essa decisão não ocorreu por acaso e tão pouco foi localizada.

O Fundef representa um dos principais pilares da política implementada pelo governo de FHC. Instituído pela EC $n^{\circ}$ 14 e regulamentado pela lei 9.424/96. Esse Fundo representou em termos de financiamento a legalização da política de omissão da União com o financiamento da educação básica. Os efeitos do Fundo foram desastrosos para os demais níveis de ensino da educação básica. No período de vigência disseminou o processo de municipalização do ensino fundamental e criou grandes demandas para o Ensino Médio. É caracterizado como um fundo de natureza contábil, com repasses automáticos de recursos aos Estados e Municípios, de acordo com o número de alunos atendidos em cada rede de ensino. É formado, no âmbito de cada Estado, por 15\% das seguintes fontes de arrecadação: Fundo de Participação dos Municípios (FPM); Fundo de Participação dos Estados (FPE); Imposto sobre Circulação de Mercadorias e Serviços (ICMS); Imposto sobre Produtos Industrializados, proporcional às exportações (IPI-exp); Desoneração de Exportações, de que trata a Lei Complementar ${ }^{\circ}$ 87/96 (Lei Kandir).

A política de financiamento, que em tese, deve provocar a efetividade do previsto constitucionalmente, ou seja, a garantia da educação como um direito social, atendeu ao longo de uma década somente um nível da educação nacional: $\mathrm{O}$ ensino fundamental. 
Em junho de 2005, o Ministério da Educação encaminhou ao Congresso Nacional a proposta de emenda constitucional para a criação do Fundo de Manutenção e Desenvolvimento da Educação Básica e de Valorização dos Profissionais da Educação (Fundeb), (PEC 415/05). É importante lembrar que a proposta do Fundeb passou por inúmeras modificações desde sua versão original como PEC no 112 de setembro de 1999, pensada pelos deputados petistas e posteriormente pelo Ministério da Educação. A PEC n ${ }^{\circ} 415$ apresente singulares diferenças de PECs anteriores ao Fundef elaboradas pelo MEC (DAVIES, 2008).

O valor a ser repassado por aluno será determinado pela União através da criação de valores-mínimos diferenciados para cada etapa e modalidade de ensino da educação básica.

Com a implantação do Fundeb a política de financiamento da educação ganha um novo rumo, uma nova dinâmica no apoio ao desenvolvimento da educação nacional. Assim, a política de financiamento do ensino médio , a partir do Fundeb, pode ser compreendida como uma possibilidade para o desenvolvimento de condições reais de construção dos objetivos propostos neste nível de ensino, a perceber a forma de distribuição dos recursos para os níveis e modalidades objetivando:

Art. 10. A distribuição proporcional de recursos dos Fundos levará em conta as seguintes diferenças entre etapas, modalidades e tipos de estabelecimento de ensino da educação básica:

I - creche em tempo integral;

II - pré-escola em tempo integral;

III - creche em tempo parcial;

IV - pré-escola em tempo parcial;

$\mathrm{V}$ - anos iniciais do ensino fundamental urbano;

VI - anos iniciais do ensino fundamental no campo;

VII - anos finais do ensino fundamental urbano;

VIII - anos finais do ensino fundamental no campo;

IX- ensino fundamental em tempo integral;

$X$ - ensino médio urbano;

$X I$ - ensino médio no campo;

XII - ensino médio em tempo integral;

XIII - ensino médio integrado à educação profissional;

XIV - educação especial;

$X V$ - educação indígena e quilombola;

XVI - educação de jovens e adultos com avaliação no processo;

XVII - educação de jovens e adultos integrada à educação profissional de nível médio, com avaliação no processo ( Lei 11.494/07).

Nessa perspectiva o Fundeb avançou em relação ao Fundef, pois abarcou toda a educação básica em seus níveis e modalidades. Com sua vigência limitada até o ano de 2020, o Fundeb passou por novas reformulações e debates a partir das muitas provocações da sociedade civil organizada e dos muitos conflitos estabelecidos entre projetos distintos do governo.

Nesse cenário, em 18 de setembro de 2019, a deputada Professora Dorinha divulgou uma Minuta de Substitutivo, ou seja, uma proposta de nova versão da PEC, em que aglutina em uma única emenda o resultado dos debates e propostas ocorridos na Comissão Especial destinada ao tema. Nesta proposta, há avanços significativos na discussão quanto ao potencial redistributivo e supletivo do novo Fundeb.

Destacamos a revisão dos critérios de redistribuição dos recursos de forma a tornar o mecanismo mais justo em termos federativos e a incorporação ao texto constitucional do Custo Aluno-Qualidade (CAQ), a ser implementado progressivamente, tendo como parâmetros a variedade e quantidade mínimas de insumos indispensáveis ao processo de ensinoaprendizagem em cada etapa e modalidade da educação básica, conforme proposto pela Campanha Nacional pelo Direito à Educação.

Esta agenda ganha ainda maior importância no contexto do Novo Regime Fiscal instituído pela EC no 95, em 2016. Isso porque tal medida, ao mesmo tempo em que proíbe a elevação de despesas primárias no âmbito da União até o exercício 
de 2036, salvo correção inflacionária, excepciona da regra do "teto de gastos" a complementação da União ao atual Fundeb (CF88, ADCT, art. 107, §6 $6^{\circ}$ I). Caso mantido esse critério na Emenda que venha a estabelecer o novo Fundeb, este acabaria por ser, na prática, a única via de manutenção ou mesmo de elevação do investimento em educação por parte do governo federal, conforme determina o Plano Nacional de Educação (Brasil, 2014).

Destacamos que no dia 21 de junho do ano corrente a Câmara dos Deputados aprovou em dois turnos a PEC 15/15 que torna permanente o Fundeb aprovado com ampla maioria em primeiro turno contando com 7 votos contra, sendo que 6 votos foram de políticos filiados ao Partido Social Liberal (PSL) e 1 voto do Partido Social Cristão (PSC), o que foi similar ao resultado em segundo turno no que se refere a quantidade votos a favor (Câmara dos Deputados).

\section{Considerações Finais}

A discussão acerca da educação como direito social e de sua qualidade passa necessariamente pela discussão do financiamento da educação. A política de financiamento da educação envolve elementos de ordem política, social e econômica que se imbricam na dinâmica da política de educação. Por isso, é necessário considerar as configurações do estado brasileiro e ainda, a responsabilidade de todos os entes federados, o marco regulatório e as fontes de recursos quando fazemos algum apontamento acerca do financiamento da educação.

Nesse cenário, a qualidade da educação brasileira fica condicionada aos ditames de uma política de segregação e exclusão que se firmou historicamente pela falta de financiamento suficiente.

Nesse cenário de análise do financiamento da educação enquanto indicador de qualidade podemos evidenciar, ainda: o Estado, por meio de sua política de ajuste fiscal, reafirma as condições de exclusão e segregação social, pois implementa um "novo modelo de desenvolvimento econômico", de parâmetros ideológicos dentro de um quadro mais geral de reestruturação da ordem política; os ditames de uma política de fundos; a descontinuidade das políticas; a centralidade dos recursos; a falta de financiamento suficiente; é necessária a efetivação de política de financiamento da educação que promova uma distribuição de recursos adequada para todos os sistemas de ensino, de forma a promover a qualidade na oferta do ensino; a CF de 1988, inciso VII, art. 206, define como um dos princípios do ensino brasileiro a garantia de padrão de qualidade, estabelece que a União deve garantir equalização de oportunidades educacionais e padrão mínimo de qualidade (Art. 211) e determina vinculação de recursos por esfera administrativa a serem aplicados para a realização dessas finalidades (Art. 212); a LDB 9.394/96, inciso IX, art. $4^{\circ}$ define que o dever do Estado para a efetivação do direito à educação será concretizado mediante a garantia de padrões mínimos de qualidade de ensino, definidos como a variedade e a quantidade mínimas, por aluno, de insumos indispensáveis ao desenvolvimento do processo de ensino-aprendizagem.

Por fim, entendemos que é necessário criar as condições de efetivação do princípio constitucional do padrão de qualidade do ensino, tal como previsto no art. 206, inciso VII da CF via políticas de financiamento da educação básica que sejam efetivas.

\section{Referências}

Alves, A. S. (2011). Financiamento do Ensino Médio público no Estado do Maranhão no período de 1996 a 2006 : possíveis efeitos da política de focalização. 2011. Dissertação (Mestrado em Educação) - Instituto de Ciências da Educação, Universidade Federal, Belém (PA)

Arelaro, L. R. G. (2007). FUNDEF: uma avaliação preliminar dos dez anos de sua implantação. Reunião Anual da ANPED, 30. Caxambu (MG). Anais eletrônicos. ANPED. http://www.anped.org.br/reunioes/30ra/trabalhos/GT05-3866--Int.pdf

Barroso, 1. R. (2006). O Direito Constitucional e a Efetividade de suas normas - limites e possibilidades da Constituição brasileira. Rio de Janeiro: Renovar.

Brasil. Constituição (1998). Constituição da República Federativa do Brasil. Brasília, DF: Senado, 1988.

Brasil. (1996). Emenda Constitucional n 14. Brasília. 
Research, Society and Development, v. 10, n. 14, e417101422256, 2021

(CC BY 4.0) | ISSN 2525-3409 | DOI: http://dx.doi.org/10.33448/rsd-v10i14.22256

Brasil. (1996). Lei no 9424, de 24 de dezembro de 1996.

Brasil. (2006). Emenda Constitucional nº 53, de 19/12/06.

Brasil. Lei no 11.494, de 20/07/07.

Brasil. MEC. Plano Nacional de Educação - Lei 10.172/2001. Brasília, 2001.

Brasil. MEC. Projeto de Lei do PNE - PL nº 8.0355/2010.

Brasil. MEC. Lei 13.005/2014. Brasília, 2014.

Brasil. MEC. Documento Final da Conferência Nacional de Educação (CONAE) 2010. MEC.

Braz, T. P. (2008). O Financiamento do Ensino Médio da Rede Estadual do Mato Grosso do Sul (1996-2006). 1998. 307 p. Tese (Doutorado em Educação) Faculdade de Educação da Universidade de São Paulo, São Paulo, 2008.

Câmara dos Deputados. (2020). Câmara aprova PEC do novo Fundeb em $2^{\circ}$ turno e amplia verba federal na educação básica. Brasília, 2020. Disponível em: https://www.camara.leg.br/noticias/678250-camara-aprova-pec-do-novo-fundeb-em-2o-turno-e-amplia-verba-federal-na-educacao-basica/

Castro, J. A. (2001). Financiamento da Educação no Brasil. Em Aberto, 18(74), 11-32.

Davies, N. (2004). Legislação educacional federal básica. Cortez, 2004.

Gouveia, A. B, Souza, A. R , Tavares, T. M. (Orgs.). Conversas sobre financiamento da educação no Brasil. Editora da UFPR.

Sarlet, I. W. (2010). A eficácia dos direitos fundamentais: uma teoria geral dos direitos fundamentais na perspectiva constitucional. (10a ed.), Livraria do Advogado Publisher.

Sarlet, I. W. (2001). Os Direitos Fundamentais Sociais na Constituição de 1988. Revista Diálogo Jurídico, Salvador, CAJ - Centro de Atualização Jurídica, 1(1). www. direitopublico.com.br.

Zanetti, T. M. (2020). A efetivação dos direitos sociais, através das políticas públicas. Um direito constitucional Conteudo Juridico, https://conteudojuridico.com.br/consulta/Artigos/30805/a-efetivacao-dos-direitos-sociais-atraves-das-politicas-publicas-um-direito-constitucional. 